\title{
Dependence of $\mathrm{pH}$ level on tribological effect of graphene oxide as an additive in water lubrication
}

\author{
A.A. Alias ${ }^{1,3^{*}}$, H. Kinoshita ${ }^{1}$, Y. Nishina ${ }^{2}$ and M. Fujii ${ }^{1}$ \\ ${ }^{1}$ Division of Industrial Innovation Sciences, \\ Graduate School of Nature Science and Technology, Okayama University \\ 3-1-1 Tsushimanaka, Kita-Ku, Okayama 700-8530, Japan \\ ${ }^{2}$ Research Core for Interdisciplinary Sciences, Okayama University \\ 3-1-1 Tsushimanaka, Kita-Ku, Okayama 700-8530, Japan \\ ${ }^{3}$ Department of Mechanical and Manufacturing Engineering, \\ Faculty of Engineering, Universiti Malaysia Sarawak, \\ 94300 Kota Samarahan, Sarawak, Malaysia \\ E-mail: aaazli@unimas.my \\ Phone: 082-584238, Fax: 082-583409
}

\begin{abstract}
A study of the effectiveness of graphene oxides (GO) dispersed in water as a lubricant additive between tungsten carbide (WC) pin against stainless steel (SUS304) plate was carried out. A 0.1 wt.\% GO was prepared and used as a lubricant under an applied load of $3 \mathrm{~N}$ for 20,000 friction cycles of reciprocating tribological testing. The results show that a GO dispersion with $\mathrm{pH} 3$ provided the lowest friction coefficient, which was approximately 0.05. Worn areas on the wear track of the SUS304 flat plate and WC ball surface were also small. The increasing $\mathrm{pH}$ obviously affected the tribological properties, where the friction coefficient increased to approximately $0.10-0.20$ in the steady state for $\mathrm{pH} 5, \mathrm{pH} 7$ and $\mathrm{pH}$ 9. Meanwhile, a GO dispersion with $\mathrm{pH} 10$ was not able to provide good tribological properties for the tested materials. The observations on microscopic images revealed the formation of tribofilms on the wear tracks for low $\mathrm{pH}$. The tribofilms caused reduction of the friction force and protected the plates from severe wear during the sliding tests.
\end{abstract}

Keywords: Graphene oxides; water lubrication; friction coefficient; $\mathrm{pH}$; wear.

\section{INTRODUCTION}

The dependents of mechanical systems such as mechanical devices and metal-working on friction and wear reduction are highly considered. In order to accommodate strong demand in this area, studies of lubricants for lubrication systems have been widely carried out. Oil-based liquid lubricants have high lubrication abilities. However, oil-based lubricants present problems especially in terms of leaks and disposal, which have led to environmental problems [1]. Therefore, alternative lubricants need to be studied. Water is obviously the best candidate as an environmentally friendly liquid. The advantages of water for use as a liquid lubricant are its high cooling capacity, good fire-resistance, and low cost $[2,3]$. However, there is a problem that the viscosity of water is too low to provide lubricating films between contact surfaces [4] . For this reason, several studies on additives to water to enable it to function as a lubricant have been carried out to address the problem $[3,5-8]$. In recent years, carbon nanomaterials such as fullerene, carbon 
nanotubes (CNT), and graphene oxides (GO) have been studied as additives to water lubricants and have clearly shown good tribological properties $[6,9,10]$. These carbon nanomaterials have graphite structures composed of $\mathrm{sp}^{2}$ bonding. Among the mentioned carbon materials, GO has received a lot of attention because of its unique properties, especially with lubricating potential $[11,12]$. GO has many carbon oxygen functional groups, which allow for dissolution in water. The size of GO will also affect the dispersion level in water [13]. In addition, the $\mathrm{pH}$ level of GO dispersion in water will affect the dissolution in water. The $\mathrm{pH}$ level of $\mathrm{GO}$ dispersions synthesized by the exfoliating process becomes acidic [14]. High acidity is not desirable for application in metal parts because of the corrosion of metal surfaces. In this study, the tribological properties of a $0.1 \mathrm{wt} . \% \mathrm{GO}$ dispersion in water were investigated using steel plates (SUS304) and tungsten carbide (WC) balls, which are generally used in metal-working. The influence of the $\mathrm{pH}$ level of GO dispersion on the tribological properties was discussed. Reciprocating sliding tests were carried out, and worn surfaces on both contact surfaces were investigated.

\section{EXPERIMENTAL PROCEDURE}

A tribometer shown in Figure 1 with a reciprocating sliding configuration was used to obtain the friction coefficients in this study. Friction tests were performed with a sliding displacement of approximately $2 \mathrm{~mm}$, a sliding frequency of $300 \mathrm{rpm}$, and duration of 20,000 cycles, under an applied normal load of 3 N. Prior to the test, both the SUS304 flat plates and WC balls were cleaned in ethanol and then water for 5 min each using an ultrasonicator. The cleaned samples were placed in an acrylic box positioned on the sliding track of the tribometer. A sufficient amount of lubricant to cover the sliding area was added (approximately $2 \mathrm{ml}$ ). The acrylic box was covered and no water condensation was observed inside the box's wall during the experiment, indicating no significant evaporation of the dispersion.

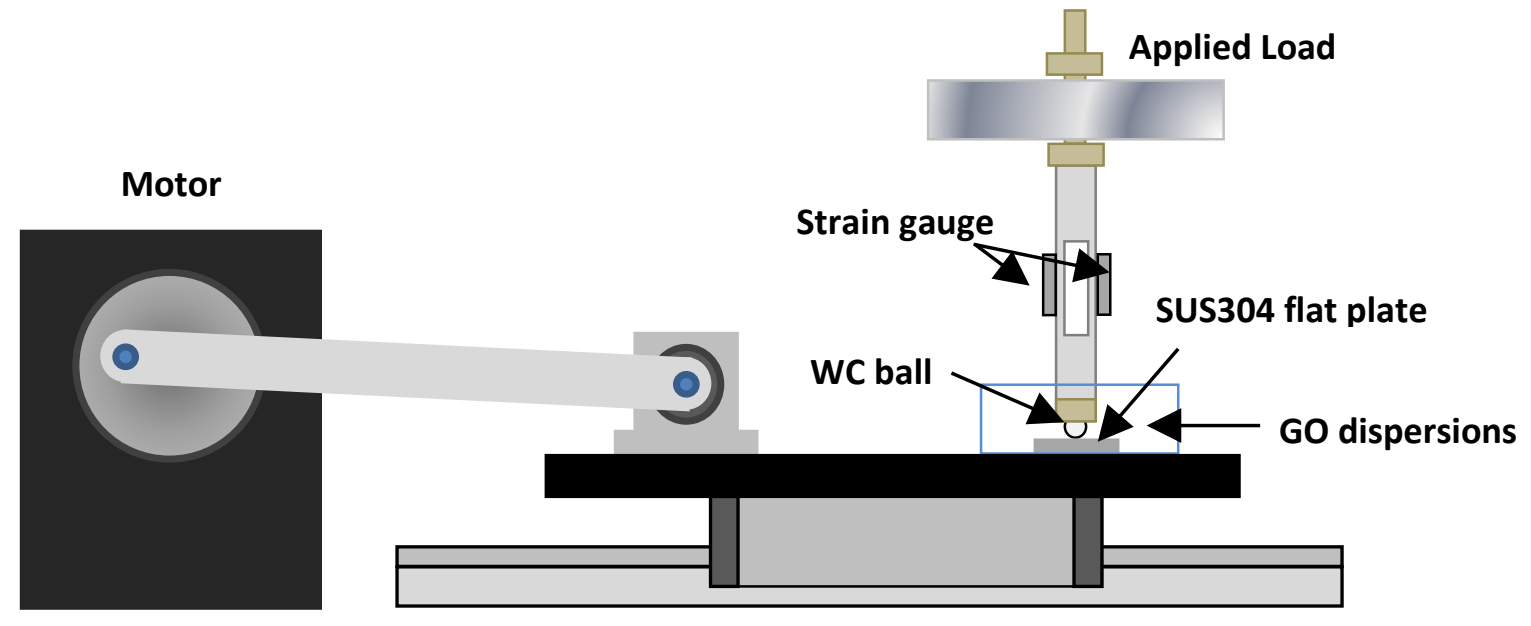

Figure 1. Reciprocating tribometer used in the study

The test materials used in this study were lapped stainless steel (JIS-SUS304) plates and sintered tungsten carbide (WC) balls with a diameter of $2 \mathrm{~mm}$. The surface roughness (arithmetic mean roughness, $R_{a}$ ) of the lapped plate surfaces was 
approximately $33 \mathrm{~nm}$, and that of the ball surfaces was approximately $2 \mathrm{~nm}$. Lubricated surfaces of the plates and balls after the sliding test were investigated by optical microscopy. All of the plates and balls were carefully washed by ultrasonicating in ethanol before the observation. The widths of the plate wear tracks were determined by the average of 3 measurements each at two different points. The concentration of the GO dispersion was $0.1 \mathrm{wt} . \%$ in this study. The $\mathrm{pH}$ regulation of the GO dispersion was carried out by adding alkaline solution, potassium carbonate $\left(\mathrm{K}_{2} \mathrm{CO}_{3}\right)$, to the original $\mathrm{pH} 3$ of the $\mathrm{GO}$ dispersion. The addition of alkaline solution was delicately conducted to adjust to $\mathrm{pH}$ 5, $\mathrm{pH} 7, \mathrm{pH} 9$ and $\mathrm{pH} 10$. The effect of increasing the $\mathrm{pH}$ level of the GO dispersion was investigated.

\section{RESULTS AND DISCUSSION}

Figure 2 shows the SEM images of the original condition of GO flakes at $\mathrm{pH} 3$ and the condition of GO flakes at $\mathrm{pH}$ 10. The SEM images were taken after the GO dispersions were dropped on silicon wafers and dried. There was no difference in the average size of over $25 \mu \mathrm{m}$ of the GO flakes in both $\mathrm{pH} 3$ and $\mathrm{pH} 10$. The increase of the $\mathrm{pH}$ level of the dispersion caused agglutination of the GO flakes. This resulted in accumulation of the GO flakes on the silicon wafer.
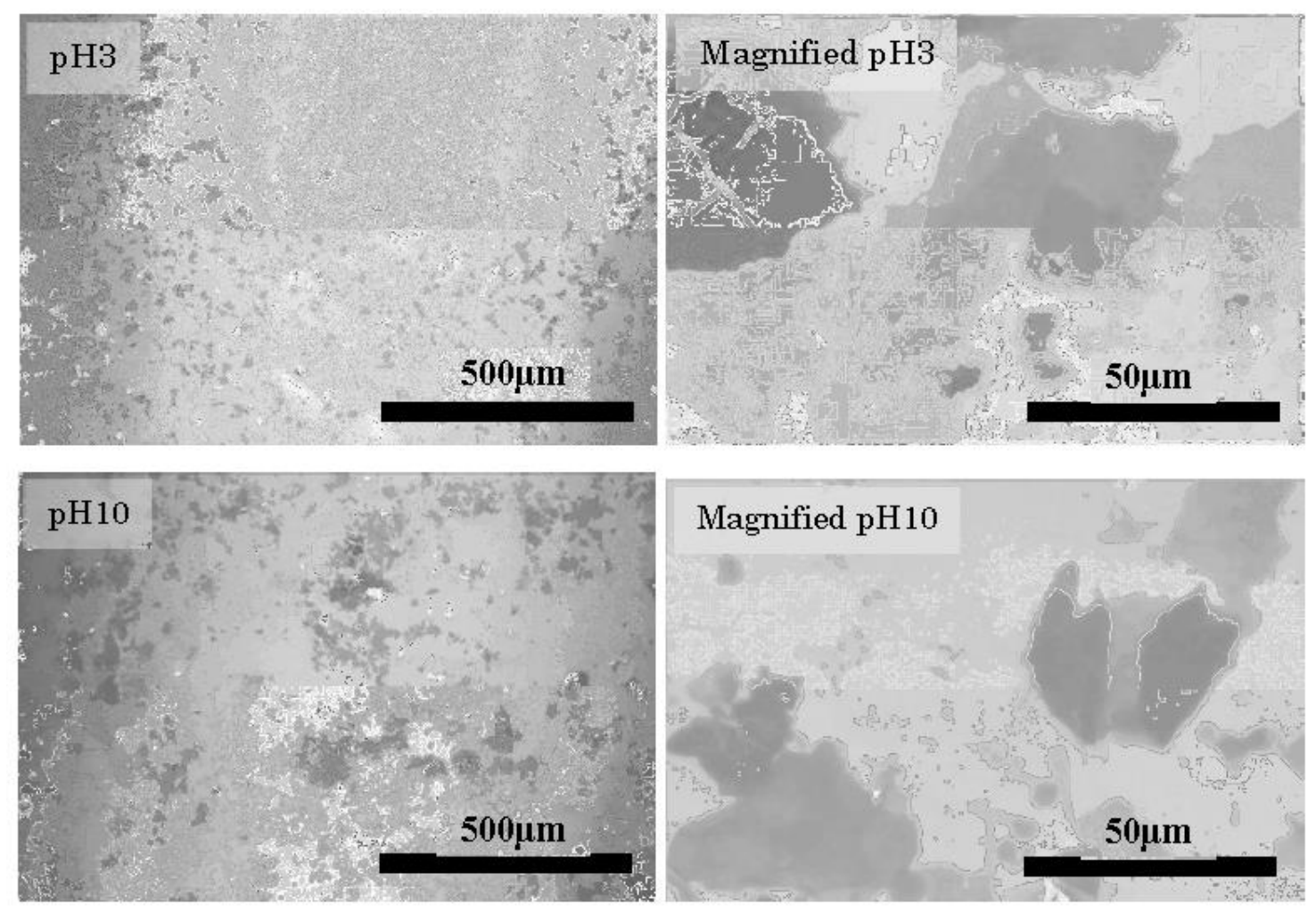

Figure 2. SEM images of GO flakes for $\mathrm{pH} 3$ and $\mathrm{pH} 10$

Figure 3 is a graph of the friction coefficients against a sliding cycle using GO dispersion at various $\mathrm{pH}$ levels. The friction coefficients of all the samples of the GO dispersions were started at approximately 0.30 . These friction coefficients were reduced in steady state for all of the dispersions except for $\mathrm{pH} 10$. The best friction coefficient was obtained at $\mathrm{pH} 3$ at extremely low 0.05 at the steady state. This was followed by $\mathrm{pH}$ 
5 and $\mathrm{pH} \mathrm{7,} \mathrm{which} \mathrm{showed} \mathrm{similar} \mathrm{values} \mathrm{of} \mathrm{the} \mathrm{friction} \mathrm{coefficient.} \mathrm{The} \mathrm{friction}$ coefficients of both dispersions were approximately 0.10 . Meanwhile, $\mathrm{pH} 9$ shows a longer running-in period, with the friction coefficient around 0.30. This friction coefficient was eventually reduced to slightly over 0.10 at 10,000 cycles. On the other hand, the GO dispersion vich pH 10 showed the highest friction coefficient, which was 0.40 to 0.50 . This friction coefficient is similar to that of water lubrication without any additive [6]. Therefore, the friction coefficient results indicate that the tribological performance provided by the GO dispersions deteriorated with increment of the $\mathrm{pH}$ level.

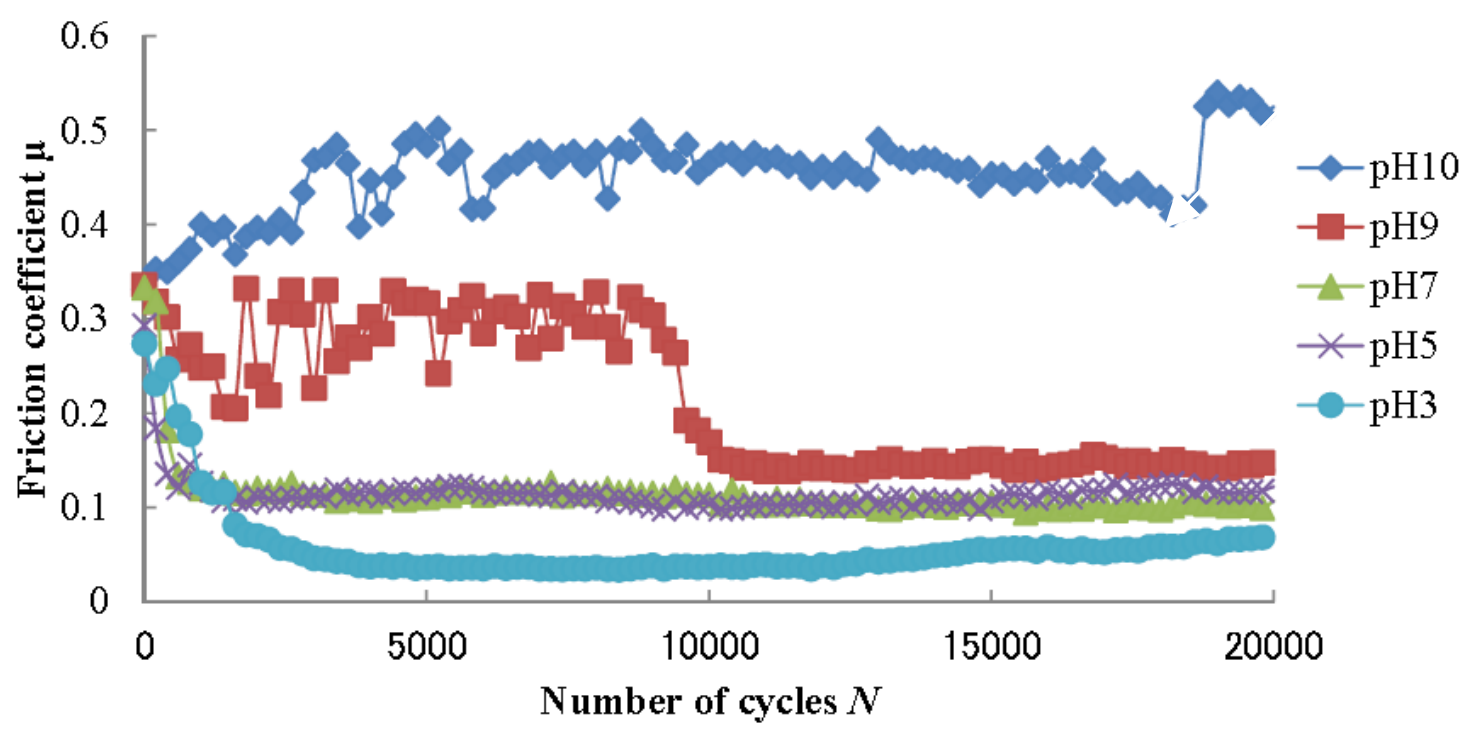

Figure 3. Friction coefficient of $0.1 \mathrm{wt} \% \mathrm{GO}$ dispersions for various $\mathrm{pH}$ levels

Figure 4 shows optical micrograph images of the wear tracks for the friction tests in the GO dispersions of $\mathrm{pH} \mathrm{3,} \mathrm{pH} 7$ and $\mathrm{pH} 10$. The observation of micrograph images indicates that tribofilms were formed in the wear tracks by the GO dispersions for $\mathrm{pH} 3$ and $\mathrm{pH}$ 7. Two types of tribofilm formed on the wear tracks for $\mathrm{pH} 3$ and $\mathrm{pH} 7$. One is an obvious thick black tribofilm, and the other is only slightly dark tribofilm. For $\mathrm{pH} 3$, the thick tribofilm which formed half way along the sliding direction was observed and would provide an extremely low friction coefficient, 0.05 . On the other hand, for $\mathrm{pH} 7$, the wear track was mainly covered by slightly dark tribofilm, and the friction coefficient was 0.10 . This friction coefficient is as low as that offered by conventional oil-based lubricants [6]. Similar tribofilms were not observed for $\mathrm{pH} 10$. There was just noticeable severe wear along the sliding direction of the wear track. Therefore, the tribofilms provided good tribological properties on the contact surfaces of the sliding materials. Moreover, the formation of tribofilm is dependent on the $\mathrm{pH}$ level of the GO dispersion. This is due to the low pH levels, which will enhance the ability of GO to disperse in distilled water, as shown in Figure 2. As a result, the low $\mathrm{pH}$ levels will provide better GO dispersions and reduce the friction coefficient. However, instead of being evenly dispersed, the SEM images in Figure 2 showed an accumulation of GO flakes for $\mathrm{pH} 10$. The conglomeration of GO flakes inhibited the formation of tribofilms between the contact surfaces. 

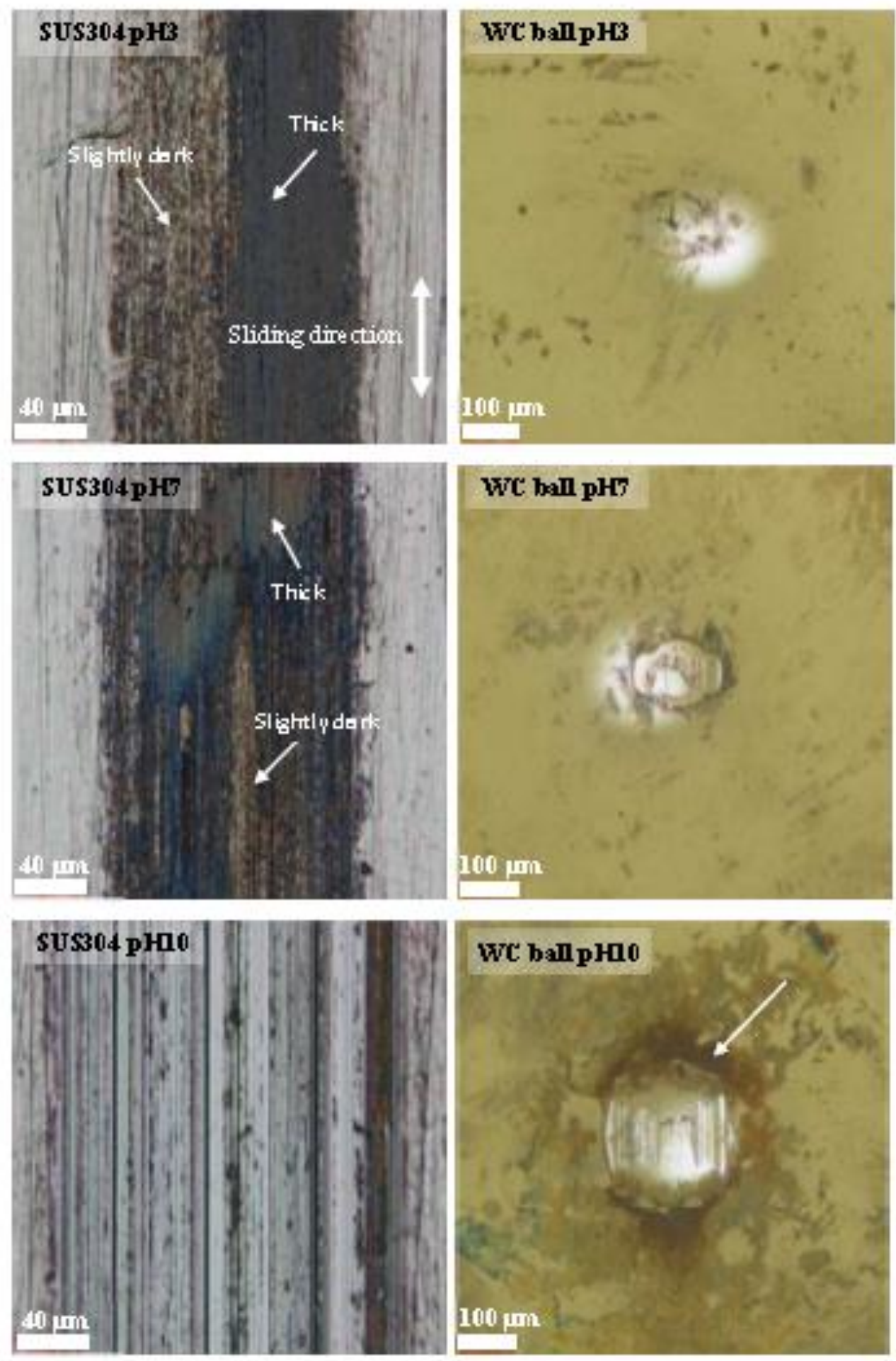

Figure 4. Micrograph images of the wear tracks on plates and wear scar on balls for $\mathrm{pH} 3, \mathrm{pH} 7$ and $\mathrm{pH} 10$ of GO dispersions.

The observations on WC balls are also shown side by side with the wear tracks in Figure 4 . The differences of the wear that occurred on each ball surface were very clear. The formations of tribofilms on the wear track of $\mathrm{pH} 3$ and $\mathrm{pH} 7 \mathrm{GO}$ dispersions obviously protected the balls from greater wear. On the other hand, severe wear on the ball by $\mathrm{pH} 10 \mathrm{GO}$ dispersion is found, which defined the poor tribological properties 
offered by the dispersion. Moreover, GO flakes substances seem to be adhered around the worn area of the ball, as shown by the arrow in the image of the WC ball for $\mathrm{pH} 10$. The adherence of GO substances on the ball surface was probably from the conglomerated GO flakes for $\mathrm{pH}$ 10. Similar formations of substances were not observable around the wear areas on the ball for $\mathrm{pH} 3$ and $\mathrm{pH}$ 7. This is because there were only the evenly dispersed GO flakes for $\mathrm{pH} 3$ and $\mathrm{pH} 7$.

Figure 5 shows the summarized data for friction coefficient, wear track depth and width for the GO dispersions with all the $\mathrm{pH}$ levels conducted in this study. These data were collected from at least 3 iterations of the tribological test for all GO dispersions. They were averaged to generate the comparison result. From the results, the $\mathrm{pH} 3$ dispersions had a very low friction coefficient at 0.05 . This was followed by $\mathrm{pH} 5$ with 0.10 . However, the amount of wear was approximately the same for both dispersions. On the other hand, although the friction coefficient for $\mathrm{pH} 7$ was 0.10 in the graph of Figure 3 , the averaged friction coefficient was 0.20 . This was due to the variation in the data obtained in other samples. The friction coefficients of $\mathrm{pH} 7$ and $\mathrm{pH} 9$ were lower than that of $\mathrm{pH} 10$. The results of the friction coefficients were also correlated to the depths and widths of the wear tracks, where the increment of friction coefficients absolutely increased the wear.

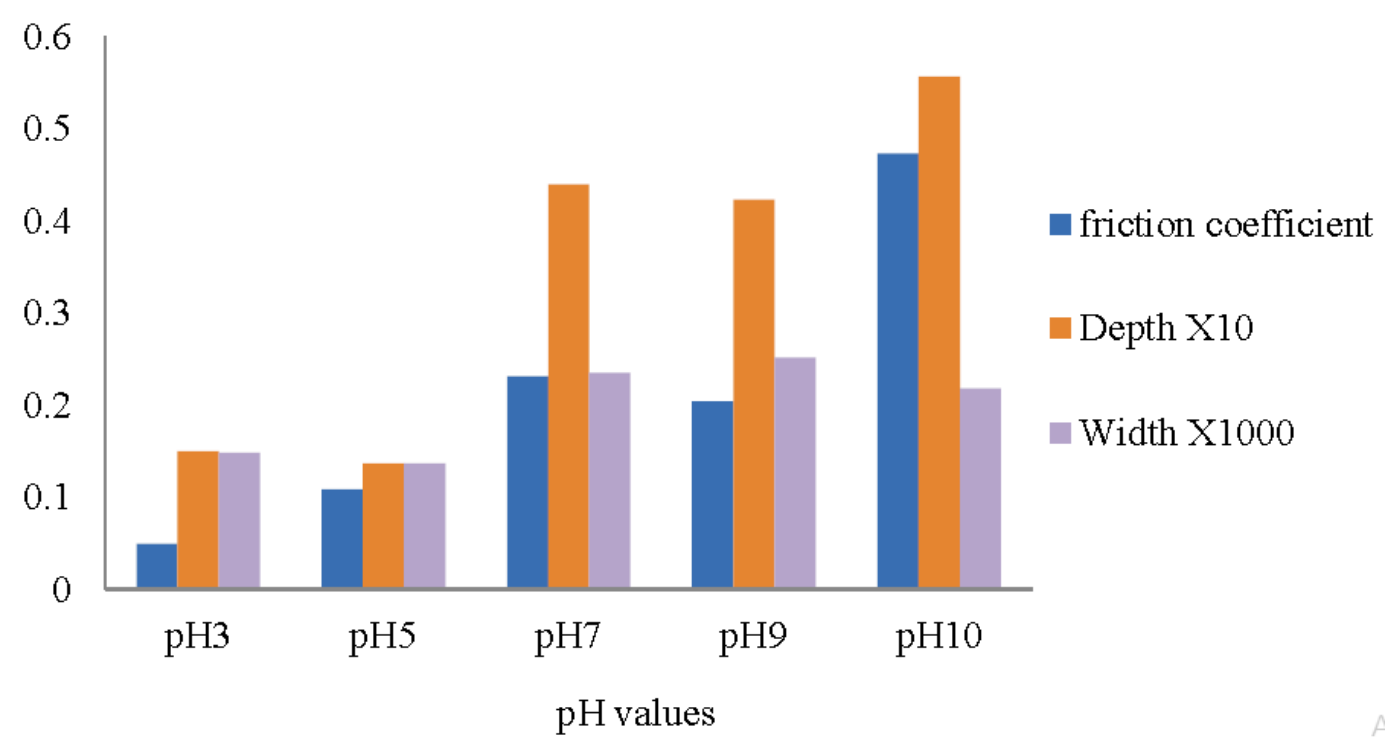

Figure 5. Summarized data of friction coefficient, depth and width of wear track by the friction test in GO dispersions (depth and width in $\mu \mathrm{m}$ )

\section{CONCLUSIONS}

In this study, the tribological properties of GO dispersions in distilled water with various $\mathrm{pH}$ levels were investigated using SUS304 steel plates and WC balls. The GO dispersion for $\mathrm{pH} 3$ provided the lowest friction coefficient with low depth and width of the worn areas on the SUS304 steel plate and WC ball. However, the friction coefficients, wear on the balls and plates were all increased by the increment of the $\mathrm{pH}$ level. The good tribological properties achieved were supported by the formation of tribofilms on the wear tracks. The formation of tribofilms was highly dependent on the $\mathrm{pH}$ level of the GO dispersions, as the amount of $\mathrm{K}_{2} \mathrm{CO}_{3}$ is significantly low. However, an experiment with 
diverse types of alkaline solution can be carried out for a clearer result for the solution's effect on the friction coefficient. In addition, further modification to the chemical chain of GO will be conducted to increase their lubricity function as an additive for water lubricant.

\section{ACKNOWLEDGEMENTS}

This research was partially supported by the Science Students Encourage Research Funding, Graduate School of Science and Technology, Okayama University and Grants in aid for Scientific Research (B) (26289028) and Research and Innovation Management Centre (RIMC), Universiti Malaysia Sarawak.

\section{REFERENCES}

[1] Pettersson A, Elisabet K, Minami I. Additives for environmentally adapted lubricants-tribo film formation. Tribology Online. 2008;3:168-72.

[2] Sukumaran J, Rodriguez V, De Baets P, Perez Y, Ando M DH. A review on water lubrication of polymers. International Journal of Sustainable Construction. 2012;3:138.

[3] Tomala A, Karpinska A, Werner W, Olver A, Störi H. Tribological properties of additives for water-based lubricants. Wear. 2010;269:804-10.

[4] Røn T, Lee S. Influence of temperature on the frictional properties of waterlubricated surfaces. Lubricants. 2014;2:177-92.

[5] Liu Y, Wang X, Pan G, Luo J. A comparative study between graphene oxide and diamond nanoparticles as water-based lubricating additives. Science China Technological Sciences. 2013;56:152-7.

[6] Kinoshita H, Nishina Y, Alias AA, Fujii M. Tribological properties of monolayer graphene oxide sheets as water-based lubricant additives. Carbon. 2014;66:7203.

[7] Lei H, Guan W, Luo J. Tribological behavior of fullerene-styrene sulfonic acid copolymer as water-based lubricant additive. Wear. 2002;252:345-50.

[8] Mori S, Kanno A, Nanao H, Minami I, Osawa E. Tribological performance of nanodiamond for water lubrication. Proceedings of the 3rd International Symposium on Detonation Nanodiamonds: Technology, Properties and Applications. 2008. p. 21-8.

[9] Ou J, Liu L, Wang J, Wang F, Xue M, Li W. Fabrication and tribological investigation of a novel hydrophobic polydopamine/graphene oxide multilayer film. Tribology Letters. 2012;48:407-15.

[10] Song H-J, Li N. Frictional behavior of oxide graphene nanosheets as water-base lubricant additive. Applied Physics A. 2011;105:827-32.

[11] Lin J, Wang L, Chen G. Modification of graphene platelets and their tribological properties as a lubricant additive. Tribology letters. 2011;41:209-15.

[12] Berman D, Erdemir A, Sumant AV. Few layer graphene to reduce wear and friction on sliding steel surfaces. Carbon. 2013;54:454-9.

[13] Cote LJ, Kim J, Tung VC, Luo J, Kim F, Huang J. Graphene oxide as surfactant sheets. Pure and Applied Chemistry. 2010;83:95-110.

[14] Konkena B, Vasudevan S. Understanding aqueous dispersibility of graphene oxide and reduced graphene oxide through $\mathrm{p} \mathrm{K}$ a measurements. The journal of physical chemistry letters. 2012;3:867-72. 